\title{
Carbon epoxy composite curing process monitoring using high resolution optical fiber sensors
}

Jakub Kaczorowski, Jan Siwek, Itxaso Parola, Barbara Jucha, Carlos Sanchez Herrera, et al.

Jakub Kaczorowski, Jan Siwek, Itxaso Parola, Barbara Jucha, Carlos Sanchez Herrera, Lukasz Szostkiewicz, Marek Napierała, Tomasz Nasilowski, "Carbon epoxy composite curing process monitoring using high resolution optical fiber sensors," Proc. SPIE 11852, International Conference on Space Optics - ICSO 2020, 118522 U (11 June 2021); doi: 10.1117/12.2599452

SPIE Event: International Conference on Space Optics - ICSO 2021, 2021, Online Only 


\section{International Conference on Space Optics-ICSO 2020}

Virtual Conference

30 March-2 April 2021

Edited by Bruno Cugny, Zoran Sodnik, and Nikos Karafolas
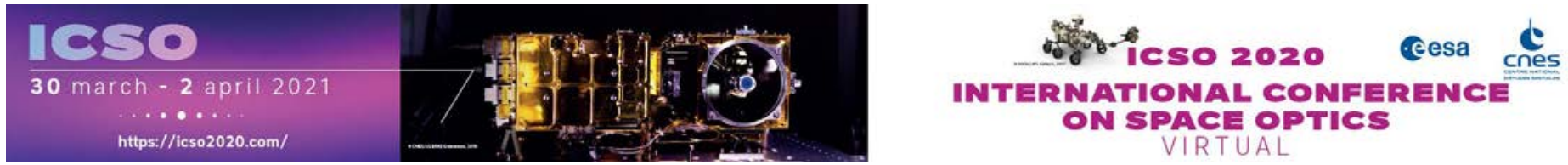

\section{Carbon epoxy composite curing process monitoring using high resolution optical fiber sensors}

\section{Cesa isoporecestings denes}




\title{
Carbon epoxy composite curing process monitoring using high resolution optical fiber sensors
}

\author{
Jakub Kaczorowski $^{1}$, Jan Siwek ${ }^{1}$, Itxaso Parola ${ }^{1}$, Barbara Jucha ${ }^{2}$, Carlos Sanchez Herrera ${ }^{3}$, Łukasz \\ Szostkiewicz ${ }^{1}$, Marek Napierała ${ }^{1}$, Tomasz Nasiłowski ${ }^{1}$ \\ 1 InPhoTech Sp. z o.o., 400A Poznanska St., Ozarow Mazowiecki 05-850, Poland \\ 2 Slaskie Centrum Naukowo-Technologiczne Przemyslu Lotniczego (SCNTPL), Nad Bialka 25, 43- \\ 502 Czechowice-Dziedzice, Poland \\ 3 Structures Section, TEC-MSS, Structures and Mechanisms Division, Mechanical Engineering \\ Department , ESTEC, Keplerlaan 1, PO Box 299, NL-2200 AG Noordwijk, The Netherlands
}

\begin{abstract}
Within this work, we present a novel approach for Structural Health Monitoring (SHM) of composite materials during the autoclave curing process. For this research, samples of Carbon Fiber Reinforced Polymer (CFRP) have been manufactured with optical fibers embedded, both in the middle of the stack and on its surface. The strain development of the CFRP during the curing process has been monitored employing the Optical Frequency Domain Reflectometry (OFDR) technique. This technique allows the conditions of the element to be tracked not only during the operational lifetime of the composite, as in most of the research in this field, but also throughout the manufacturing process. The reported measurements demonstrate the potential of distributed optical fiber sensors for monitoring CFRP structures while their manufacturing, providing a unique opportunity for early detection of damages that may result in critical failures (e.g. delamination and debonding) and for improving the quality of the manufacturing processes and the final strength of the product.
\end{abstract}

Keywords: Composite materials, CFRP, distributed optical fiber sensors, optical fibers, strain measurement, OFDR, curing process, structural health monitoring

\section{INTRODUCTION}

Carbon Fiber Reinforced Polymer (CFRP) is an extremely strong and lightweight composite material widely used in aviation [1], space [2], automotive [3], and civil applications [4]. The use of CFRP is increasing in number and volume in the last years and the variety of applications that require their stiffness and specific strength is continuously growing.

The potential of these structures has been boosted in recent years by the creation of the so-called intelligent composites [5] that provide active structural health monitoring information. An intelligent CFRP composite can be created by integrating an optical fiber into its structure and using it as a sensor. The concept of optical fiber distributed sensing in composite materials has been known and used for at least 30 years [6]. This technology enables the creation of "intelligent materials" which allows for continuous structural health monitoring and status diagnosis during their operational lifetime [7] [8]. Several parameters can be monitored, such as strain and temperature, delivering a full picture of the condition of the material [9]. This approach enables not only to control the state of the material and prevent the damage of the structure but also to find critical faults such as delamination or debonding that may result in failure.

There are other well-known conventional technologies for the structural health monitoring of CFRP structures, such as scanning methods or point sensors like electronic sensors and fiber Bragg gratings [10][11][12][13]. However, these technologies present several drawbacks, like being cost and time consuming, presenting limited access or view to certain areas in the structure, and having a complex installation including the requirement of a lot of cabling. Having a distributed optical fiber sensor integrated directly into the material reduces the complexity of the system, therefore the costs and the overall weight of the structure are also reduced - which can be crucial in some applications. It also provides continuous monitoring along the whole length of the fiber without dead zones. Moreover, an embedded optical fiber makes the sensors an integral part of the composite structure, enhancing the potential of monitoring not only during the operational lifetime of the structure but during their entire life including manufacturing. All these benefits combined with the common 
advantages of optical fibers [14] - like immunity to electromagnetic interferences - make "smart composites" the perfect technology for the aerospace, aviation, and automotive industries.

In this paper, we demonstrate the potential of distributed optical fiber sensors for the monitoring of the material autoclave curing process during the manufacturing of CFRP composites. A similar approach was already tested in other works with the usage of other composite production methods or optical fiber point sensors [15][16][17][18]. However, to the best of our knowledge, this is the first time the combination of distributed sensing OFDR technique with the autoclave prepreg curing method is studied.

\section{GOAL OF THE MEASUREMENTS}

As mentioned before, it is crucial to monitor a CFRP structure while its operational lifetime, but it is equally important to analyze the manufacturing processes to address beforehand any structural failure risk. During the manufacturing of CFRP structures, some defects that are invisible or barely visible with the naked eye may occur if it is not monitored properly. These possible failures may result in for example delamination, debonding, or cracking which can be fatal once the structure is launched. At the moment, to detect the presence of defects inside the materials, a Non-Destructive Inspection is performed after the manufacturing. However, the main limitation of these techniques is that the composite can be checked only at the moment of the test, not during the whole operating time. All these failures can be detected with SHM based on a distributed optical fiber sensor that detects strain changes in the affected regions.

The goal of the presented experiment was to prove that it is possible to measure the evolution of the induced strain during the curing of the composite. Composite curing is a fundamental step in the manufacturing of CFRP structures. However, monitoring this step is complex due to the harsh conditions required (high temperature and increased pressure) and to the difficult and limited access (the composite structures are placed inside a vacuum bag for the autoclave process). Moreover, autoclaves are not adapted to offer the possibility of exiting optical fibers or other additional sensors for connecting them with an interrogator unit. For these reasons, generally, the strain development during the process is not monitored.

However, gathering knowledge about the precise values of the residual stresses generated in the manufacturing of the composite material can positively influence the quality of the process and the final strength of the product. Distributed optical fiber sensors play a key role in this application as they can be employed in such harsh conditions and they use a minimum space inside the autoclave chamber. This technology can provide a better understanding of the residual stresses that are generated during the curing and that may result in the weakening of the composite structure. Moreover, the proposed solution could also be employed to monitor the stress development in a broken structure that is being repaired through a curing process, like for example the addition of composite layers in weakened areas.

\section{TEST SETUP}

\subsection{Optical fiber distributed sensors}

Optical fibers, besides the well-known applications in the telecom sector, can also be used as optical sensors to detect a wide range of parameters, like temperature, strain, or pressure. They present many advantages in comparison to conventional electronic sensors, such as lightweight, reduced space and cost, flexibility, and electromagnetic interference immunity[14].

Optical fiber sensors were initially realized as pointwise sensors, however, distributed sensors have gained most of the attention in the last years due to their key advantages. These specialty sensors benefit from an overall cost reduction by allowing measurements of tens of kilometers with a high spatial resolution and no dead zones, and they provide real-time monitoring of the health of the structures and their environmental conditions in a variety of applications [19]. There exist several distributed sensing techniques, but recently, the Optical Frequency Domain Reflectometry (OFDR) has gained significant attention in distributed sensing applications due to its relatively high spatial resolution combined with a large dynamic range. The ability of this technology to measure a high range of strain (even small changes in residual stresses), and the capacity the optical fibers provide to perform measurements in the presence of high temperature and pressure, make this type of sensor the perfect tool for monitoring the autoclave curing process of a CFRP structure. Therefore, a single fiber embedded in a composite material can provide a full understanding of the health of the whole structure at once. 
In this work, we employ the OFDR technique with a strain resolution of $1 \mu \varepsilon$, a sampling resolution of $2 \mathrm{~mm}$, and a repetition rate of $30 \mathrm{~s}$.

\subsection{Test samples}

To analyze the strain evolution during the composite curing process six samples were manufactured. The samples consisted of a prepreg stack with optical fibers embedded. For the sake of comparison, we employed 2 different test layouts (3 samples per each). The first one with the optical fibers embedded in the middle of the composite stack, and the second one with the optical fibers at the top of the composite stack. In all the samples, the optical fiber crosses the composite sample longitudinally 3 times to provide 3D measurements of the structure strain. The sample layout is presented in Figure 1.

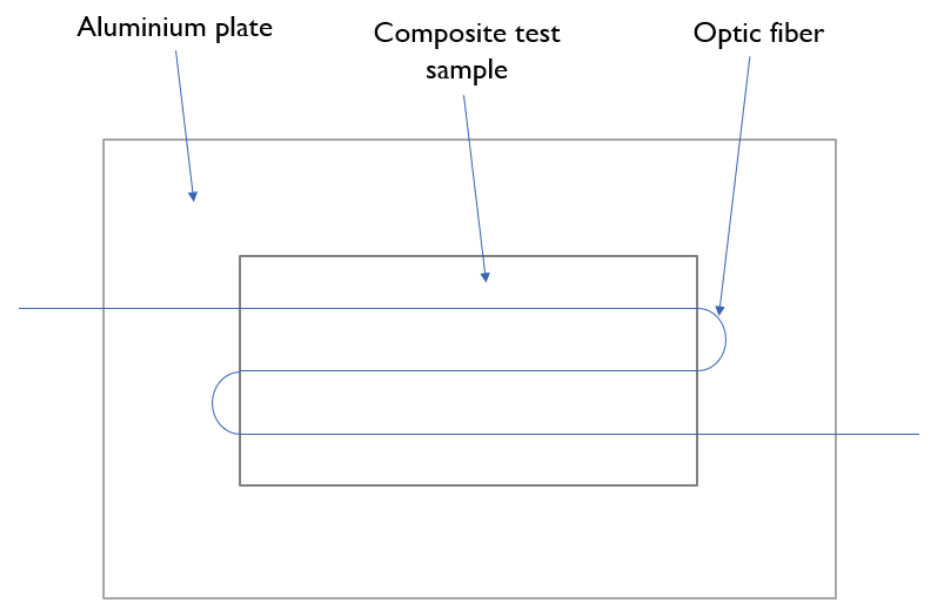

Figure 1. Sample and optical fiber layout.

The material used for the samples is the space-qualified M18/M55J prepreg. This material was chosen to reproduce as close as possible a final application of the technology. The type of optical fibers employed is SMF (Single Mode Fiber) with a reduced diameter and a special coating. This fiber was chosen due to its high-temperature resistance and its minimum influence on the structure of the composite [20]. The sample dimensions are specially designed considering the size of the curing chamber. All samples were put inside a vacuum bag and placed on aluminum plates. An example of one of the samples prepared for curing is shown in Figure 2.

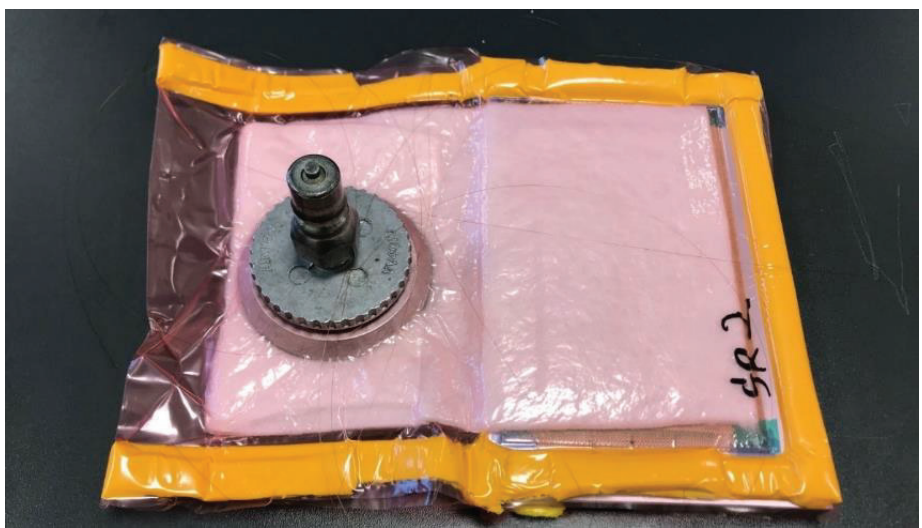

Figure 2. Sample in the vacuum bag before curing. 


\subsection{Composite curing setup}

The setup used for the curing of the tested samples is presented in Figure 3. This schematic represents the employed measuring setup which was prepared to ensure the optimal conditions for M18/M55J prepreg composite material curing and the possibility to route the optic fibers outside the pressure chamber.

The test setup was based on a curing pressure chamber (1) connected to a vacuum pump (2) and a compressor (3) to apply the proper values of pressure and vacuum in the vacuum bag. The chamber was connected to a thermal regulation device (4) working based on the information provided by a thermocouple in a feedback loop (5). To perform the measurements, the test sample (7) was connected to an interrogation unit (6) using an optical fiber pigtail coming out from the thermal chamber (8). The temperature and pressure change was applied following the standard curing procedure.

The pressure is set at 6 bars for the whole process. The vacuum also remains constant in the whole process at -0.25 bar. The first stage of the process begins with heating the sample from room temperature to $180{ }^{\circ} \mathrm{C}$ at a constant speed of 1.2 ${ }^{\circ} \mathrm{C}$ per minute. Once the maximum temperature is reached the curing stage begins, where the temperature remains constant at $180{ }^{\circ} \mathrm{C}$ for 2 hours. Finally, in the last stage, the sample is cooled down at a constant speed of $1.2{ }^{\circ} \mathrm{C}$ per minute. When the temperature reaches $50{ }^{\circ} \mathrm{C}$ the pressure and vacuum are released and the process is finished.

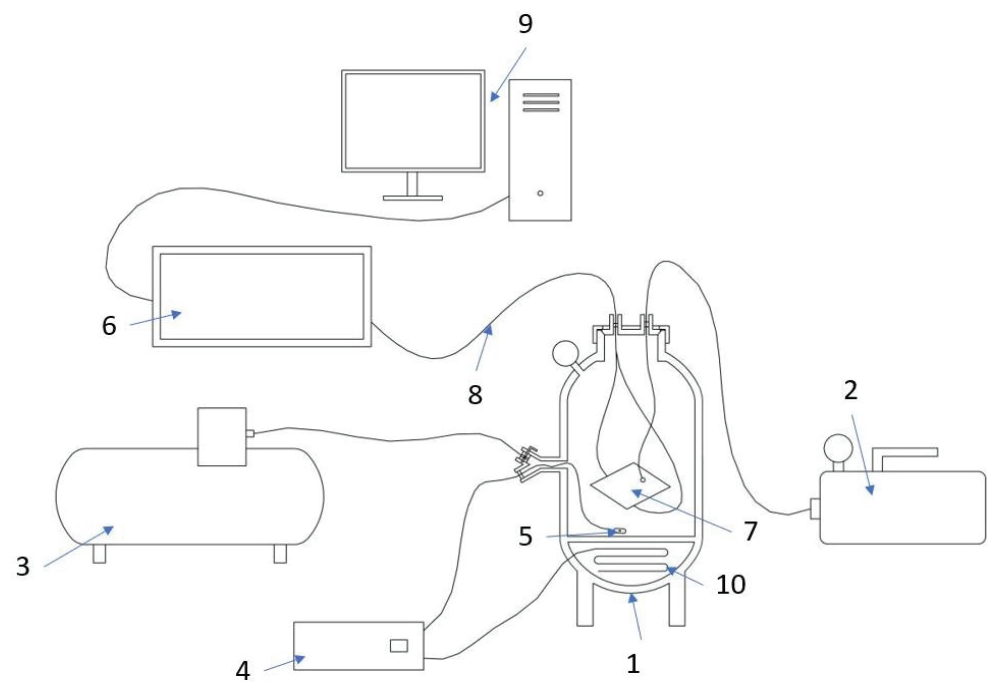

Figure 3. Composite curing setup.

\section{RESULTS}

\subsection{Predictions}

As beforementioned, in a thermal curing process, three main stages can be distinguished: heating at a constant gradient of temperature, curing at a constant temperature, and cooling at a constant gradient of temperature. Based on the thermal coefficients of the materials involved in the test (carbon fiber, epoxy resin, aluminum, and glass optical fiber) the following predictions were made: In the first stage, the strains in the sample should grow (elongation) due to the positive thermal coefficients of the materials; In the second stage the strains should remain the constant or get smaller as the resin undergoes a cross-linking process; In the third stage, the strains should get smaller and even change from elongation to compression due to the different thermal coefficients of the materials [21][22]. 


\subsection{Experimental results}

The optical fibers were spliced in series to measure all the parts embedded into composite simultaneously. This is possible due to the use of distributed sensing, which allows achieving measurements in each part of the fiber. The OFDR traces were continuously recorded along the whole curing process.

The raw data gathered from the device was in form of spectral shift. According to the current state of the art, it is assumed that the spectral shift is linearly proportional to the temperature or strain change of the sensing fiber. The proportionality coefficient, called respectively temperature sensitivity or strain sensitivity is a characteristic value for each particular fiber and it depends on the material and processes used in the manufacturing of the fiber. In the case of a typical single-mode fiber, those coefficients are equal to: $-1,25 \frac{\mathrm{GHz}}{{ }^{\circ} \mathrm{C}}$ and $-0,15 \frac{\mathrm{GHz}}{\mu \varepsilon}$. The whole relation can be defined with the following equation:

$$
\Delta v=S_{T} \cdot \Delta T+S_{\epsilon} \cdot \Delta \epsilon
$$

$\Delta v-$ spectral shift (wavelength frequency),

$S_{T}, S_{\varepsilon}$ - temperature and strain sensitivity coefficients,

$\Delta T, \Delta \varepsilon$ - temperature and strain change regarding equilibrium state.

As can be seen, the spectral shift depends on both temperature and strain. As during the experiment both parameters could be changed (the temperature due to the heating and the strain due to the residual stress development) a solution to distinguish both effects must be provided. Therefore, apart from the testing fibers we employed an additional fiber loop attached on the surface of the vacuum bag for reference and temperature compensation. The fiber was positioned in the way that it was convoluted in the area of the composite sample (it was not excessing its surface). This fiber was exposed only to temperature changes, not to other forces. The signal from the fiber inside the composite was compensated with the temperature data from the reference loop in postprocessing. Since both strain and temperature measurements were conducted optically, the compensation process could be easily provided by the simple subtraction of the raw data measurements. This way, the data from the fiber inside the composite could be translated into strain.

The compensated spectral shift for one of the samples is presented in Figure 4, the data of an OFDR trace before the curing process on the left, and after curing at room temperature on the right. The green areas marked on the plots correspond to the temperature reference fiber loop, whereas the red areas correspond to the optical fibers inside the composite. As can be seen, some residual stresses remain in the red areas after the curing process is finished.
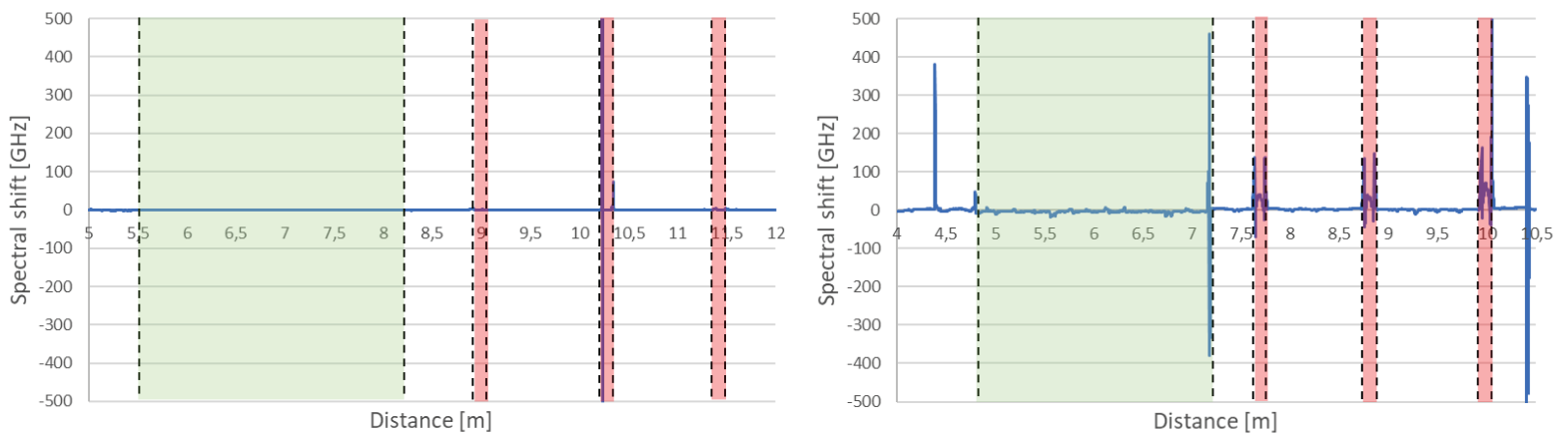

Figure 4. Spectral shift before and after curing.

After processing all the OFDR traces and obtaining the strain values from the spectral shifts, the evolution of the induced strain as a function of the curing time can be plotted. Figure 5 and Figure 6 show the results obtained for a sample with the optical fiber in the middle of the composite stack, and a sample with the optical fiber on the top of the stack respectively. For the sake of simplicity, only the results of these two samples are shown, as a repeatable pattern was found for all the 
samples of the same type. The plotted data correspond to a single fiber section that crossed the sample longitudinally. The strain data were averaged for the fiber length to get the mean value of the strain change for every timestamp.

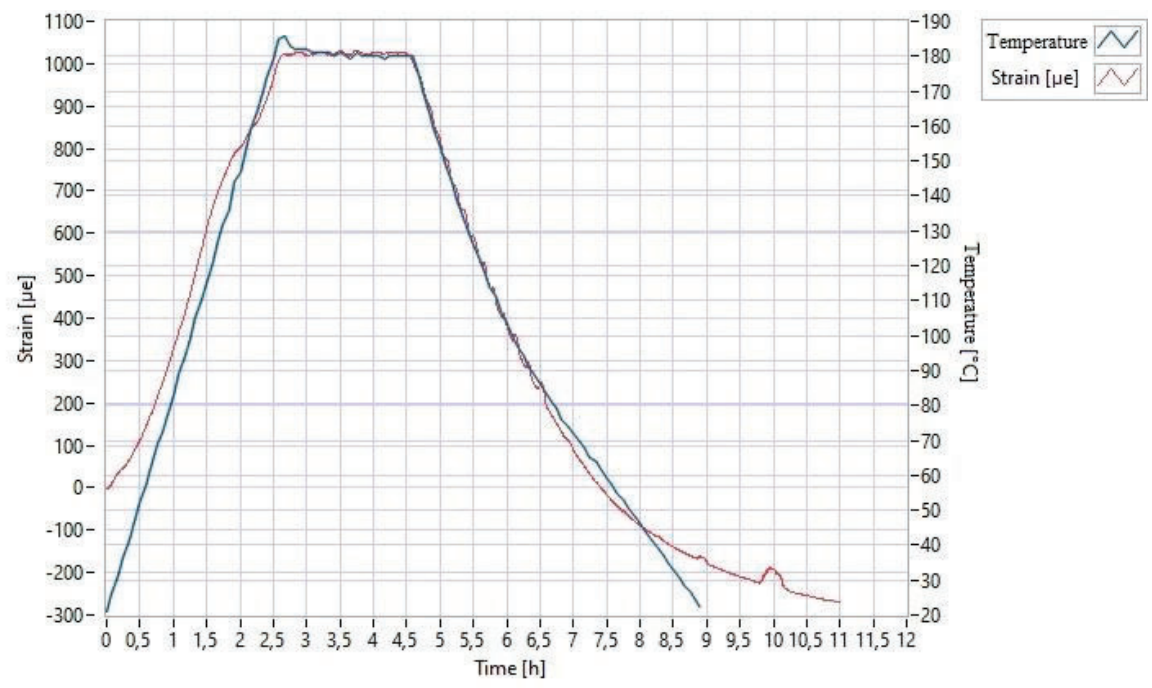

Figure 5. Evolution of the strain during curing - sample with fibers in the middle of the composite stack.

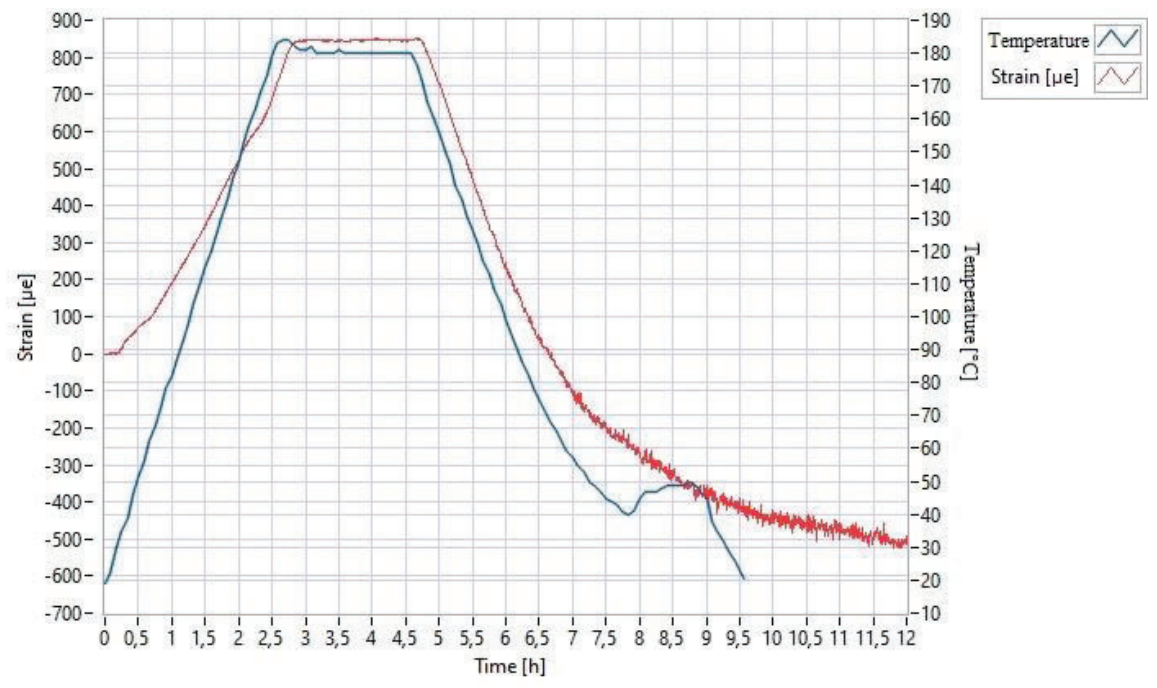

Figure 6. Evolution of the strain during curing - sample with fibers on the surface of the composite stack.

Based on the plots above, three main strain scenarios can be identified. During the heating stage, positive strain starts appearing due to the elongation of the sample; during the curing process (stage exposed to a constant temperature) the strains remain constant; and during the cooling stage, the value of the tensile strains decreases with temperature. However, at a certain time, we can observe a change in the strain values from positive to negative (from elongation to shrinking). At this stage, the effect of the strain induced inside the sample during the curing process is observed. These results are in agreement with the predictions carried out before performing the test. It should be mentioned that only one major difference was found between the sample types. Through the curing process, the samples were heated to a certain temperature to activate the thermoset process and then cooled down. The samples with optical fibers in the top of the stack presented shrinkage strains earlier than the samples with the optical fibers embedded in the middle of the stack. 
As mentioned before, the analysis presented above was performed by using the averaged value of strain along one of the fiber sections inside the sample to show the general dependence between temperature, time, and the induced strain. However, the strain measured along the fiber can also be visualized as functions of the curing time and the sample length providing a 3D map of the process. An example of this visualization is shown in Figure 7.

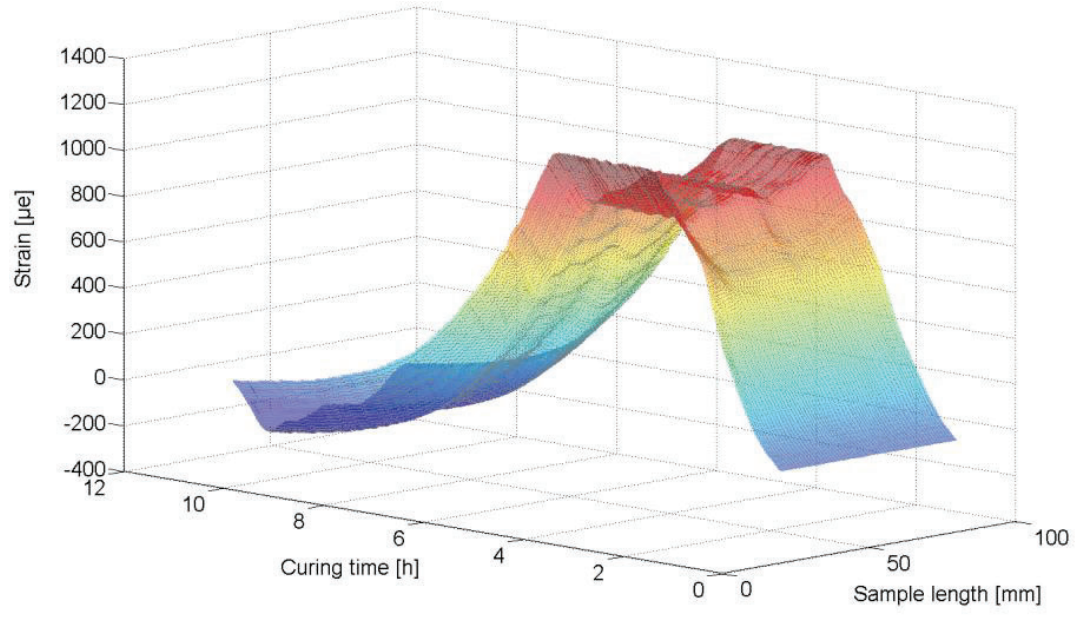

Figure 7. 3D Map of the strain distribution in the sample during the curing process.

\section{CONCLUSIONS:}

The presented work demonstrates the possibility to continuously monitor the composite thermal curing process with the use of an optical fiber distributed sensor. The obtained data is consistent with the test predictions. Three sets of two types of samples were analyzed presenting a repeatable pattern. The parameters set in this experiment show that this kind of test can be performed in other manufacturing methods that are conducted in similar conditions. The maximum long term temperature set in the test was $180^{\circ} \mathrm{C}$, the measured strain was in the range from $1600 \mu \varepsilon$ to $-550 \mu \varepsilon$, and the test was conducted under a pressure of 6 bar and vacuum of $-0,25$ bar. The preparation and analysis of two sets of samples (fiber on the surface and in the middle of the stack) allowed us to conclude that for the composite layers on the top shrinkage strains were detected earlier than in the samples with fibers in the middle of the composite stack due to the only reason of the location of the fibers.

The presented technology allowed gathering data all along the curing process. Moreover, as distributed sensing enables measurements in the whole fiber length, strain gradients along the sample can be analyzed. The obtained results provide a detailed analysis of the development of the strains induced in the curing process and provide a potential monitoring solution. With the application of distributed sensing technology in the composite curing process, SHM data is available from the very beginning of the CFRP life cycle and not only for its operational lifetime. Moreover, the gathered data can possibly be employed for composite production optimization and for the early detection of possible damages in manufacturing that can remain invisible to other techniques.

\section{ACKNOWLEDGMENTS}

European Space Agency, Project "Integrated optical fibres in launcher and spacecraft composite structures" $(4000123665 / 18 / \mathrm{NL} / \mathrm{BJ})$

The National Centre for Research and Development, Project "Innowacyjne światłowody dedykowane do integracji ze strukturą kompozytu polimerowego wzmacnianego włóknem węglowym do zastosowań w nowoczesnych systemach diagnostyki strukturalnej o wysokiej rozdzielczości - akronim projektu fibrous” (POIR.04.01.01-00-0031/17) 


\section{REFERENCES}

[1] Herrmann A.S., Zahlen P.C., Zuardy I. „Sandwich Structures Technology in Commercial Aviation - present applications and future trends." Sandwich Structures 7: Advancing with Sandwich Structures and Materials. Springer, Dordrecht. 13-26. (2005)

[2] Mrazova. M, „Advanced composite materials of the future in aerospace industry”, INCAS BULLETIN, Volume 5 , Issue 3/ 2013

[3] Joachim S., „Carbon composites in automotive structural applications. ” EuCIA: Composites and Sustainability (2016).

[4] Hollaway L.C. „A review of the present and future utilisation of FRP composites in the civil infrastructure with reference to their important in-service properties" Construction and Building Materials, Volume 24, Issue 12, 2010, Pages 2419-2445

[5] Aliabadi M. H.,Sharif Khodaei Z., „Structural health monitoring for advanced composite structures.” Vol. 8. World Scientific, 2017.

[6] J. William B. Spillman, „Composite integrity monitoring”. US Patent US4983034A, 1989.

[7] G. Alfredo, F.-L. Antonio i F. Patricia, „Damage detection in composite structures from fibre optic distributed strain mesurements," w EWSHM - 7th European Workshop on Structural Health Monitoring, Nantes, France, 2014.

[8] G. Rajan i B. G. Prusty, „Structural Health Monitoring of Composite Structures Using Fiber Optic Methods”, Boca Raton, Florida: CRC Press, 2017.

[9] Ding Z., Wang C., Liu K., Jiang J., Yang D., Pan G., Pu Z., Liu T. „Distributed Optical Fiber Sensors Based on Optical Frequency Domain Reflectometry: A review.” Sensors, 2018

[10] Frovel, M. \& Olmo, E. \& Pintado, Jose-Maria. (2008). Optical fiber Bragg grating sensors embedded in CFRP composites for structural health monitoring of aerospace structures.

[11] Donald G. Myers, "Method for measurement of residual stress and coefficient of thermal expansion of laminated composites", School Of The University Of Florida, University Of Florida, 2004

[12] Maxwell, Antony \& Broughton, W. \& Lodeiro, M \& Shaw, R. (2009). Measurement of Residual Stresses and Strains in Carbon Fibre Composites.

[13] Nawab, Yasir \& Boyard, Nicolas \& Sobotka, Vincent \& CASARI, Pascal \& Jacquemin, Frédéric. (2011). A Device to Measure the Shrinkage and Heat Transfers during the Curing Cycle of Thermoset Composites. Advanced Materials Research. 326. 19-28. 10.4028/www.scientific.net/AMR.326.19.

[14] Güemes A., Fernández-López A., Soller B. „Optical Fiber Distributed Sensing - Physical Principles and Applications." Structural Health Monitoring. 2010, 9(3):233-245

[15] Daniel Martínez Sánchez, Matthieu Gresil, Constantinos Soutis, "Distributed internal strain measurement during composite manufacturing using optical fibre sensors", Composites Science and Technology, Volume 120, 2015, Pages 4957, ISSN 0266-3538, https://doi.org/10.1016/j.compscitech.2015.09.023.

[16] Jung-Ting Tsai, Joshua S. Dustin, Jan-Anders Mansson, Cure strain monitoring in composite laminates with distributed optical sensor, Composites Part A: Applied Science and Manufacturing, Volume 125, 2019, 105503, ISSN 1359-835X,https://doi.org/10.1016/j.compositesa.2019.105503.

(https://www.sciencedirect.com/science/article/pii/S1359835X19302520)

[17] S.S.J. Roberts, R. Davidson, Cure and fabrication monitoring of composite materials with fibre-optic sensors, Composites Science and Technology, Volume 49, Issue 3, 1993, Pages 265-276, ISSN 0266-3538, https://doi.org/10.1016/0266-3538(93)90108-S.

[18] Haixiao Hu, Dongfeng Cao, Martyn Pavier, Yucheng Zhong, Lei Zu, Lisheng Liu, Shuxin Li, Investigation of non-uniform gelation effects on residual stresses of thick laminates based on tailed FBG sensor, Composite Structures, Volume 202, 2018, Pages 1361-1372, ISSN 0263-8223, https://doi.org/10.1016/j.compstruct.2018.06.074. 
[19] Dominguez-Lopez A., Szostkiewicz Ł., Napierała M., Nasiłowski T, „Distributed Optical Fiber Sensors based on Photonic Crystal Fibers for Advanced Sensing Applications", 12th Integrated Optics - Sensors, Sensing Structures and Methods, 2017

[20] E. Voet, T. Ahmed, E. Lindner, G. Luyckx, A. Brødsjø and J. Degrieck, "Smaller Diameter Optical Fibre Sensor for Automated Embedding in Composite Laminates," in 7th European Workshop on Structural Health Monitoring, Nantes, 2014

[21] Kravchenko, O., Kravchenko, S., \& Pipes, B. (2016, 01). Chemical and thermal shrinkage in thermosetting prepreg. Retrieved from researchgate.net: https://www.researchgate.net/publication/283450853_Chemical_and_thermal_shrinkage_in_thermosetting_prepreg

[22] Dong, C., Li, K., Jiang, Y., Arola, D., \& Zhang, D. (8.01.2018), Evaluation of thermal expansion coefficient of carbon fiber reinforced composites using electronic speckle interferometry, Optics Express. 